\title{
POSSIBLE ACCEPTABILITY OF WIRELESS DRUG DELIVERY SYSTEM (WDDS) AMONG CHRONIC AILMENT PATIENTS IN KARACHI, PAKISTAN
}

\author{
"Tariq Ali", Auwais Ahmed Khan ${ }^{1}$, Muhammad Fayyaz ${ }^{2}$, Asfia Tariq ${ }^{3}$
}

\author{
${ }^{1}$ Dow College of Pharmacy, Dow University of Health Sciences, Karachi, Pakistan \\ ${ }^{2}$ Department of Pharmaceutics, Faculty of Pharmacy, University of Karachi, Karachi, Pakistan \\ ${ }^{3}$ Dr. Fasih's ENT \& General Hospital, Karachi, Pakistan \\ *Corresponding Author: TARIQ ALI, Email:tariqali155@yahoo.com
}

Received 06 Dec 2012; Review Completed 22 Dec 2012; Accepted 03 Jan 2013, Available online 15 Jan 2013

\begin{abstract}
Pakistan as being the part of a low average income country, where life is not easy for common man, the new technology acceptability in health management is a real risk. The case become worst where people totally rely on traditional method of treatment instead of highly advanced one. The use of wireless controlled microchips is an emerging technology in drug delivery system. The microchips devices implanted in patients and controlled by microprocessor wireless communication. Wireless drug delivery system (WDDS) has the potential to improve patient compliance. The aim of present study is to check the possible acceptability of WDDS in chronic ailment patients in Karachi, Pakistan. A questionnaire based survey was conducted among three different categories of patients with chronic illness after giving a brief awareness of WDDS technology. A total of 150 participants took part in the study. A large proportion of participants were believed in new technology for cure of their chronic disease. The study results also showed that about $65 \%$ of chronic ailment patients will rely on western world drug research trials. About $75 \%$ have shown consent to adapt WDDS technology after complete trial data. From the study performed it clearly understood that any effort and future development in WDDS will be highly appreciated and adopted among chronic ailment patients in Karachi, Pakistan.
\end{abstract}

Key Words: Microchip, wireless controlled drug delivery system (WDDS), chronic ailment patients, Karachi, Pakistan

\section{INTRODUCTION}

In many clinical specialties including neurology, cardiology and orthopedics, implantable medical devices are frequently used. Devices like joint replacements, pain pumps and pacemakers perform an fludic, mechanical, or electronic function to lead patients to perform their normal body functions. To reduce morbidity and improve efficacy, many manufacturers of device have integrated chemicals or drugs into medical implants in the past decade. For instance when comparing the Drug-eluting stents with bare metal stents it was found that drug eluting stent reduce instent restenosis. ${ }^{1} \quad$ Patient compliance is a major problem where frequent dose administration is required, in these cases a health professionals are in dare need to have an automated drug delivery system.

A drug delivery system can be defined as mechanism to introduce therapeutic agent into the body. Drug delivery systems have had a high impact on technology, greatly enhance the presentation of many current drugs \& facilitate the use of new therapies. ${ }^{2}$ Santini el al., first developed one class of combination products featuring ondemand drug release capabilities that was a microchip with many reservoirs containing discrete doses of drug . $^{3-5}$

Micro-electronic devices have become essential part of today's life. They are present in our cellular phones, computers and automobiles. ${ }^{\mathbf{6}}$ Technology enable to develop revolutionary opportunities in every field of life and this stimulated the development of innovative techniques in drug delivery system. Recent advances in the field of drug delivery system created the possibility to meet the patient need. For this a new drug delivery system is design that is wireless control drug delivery system that work through "microchip", 7

\section{Need of wireless drug delivery system}

Wireless drug delivery system has the capability to improve patient compliance as patient compliance is a major issue, especially in chronic diseases. Such issues include 'simply forgetting, that is 65\%; 'concerns about the drugs' that is 45\%; and feeling the 'drug is unnecessary' is $43 \%$, it is just because of long term use and complex drug regimen. ${ }^{\mathbf{8}}$ Traditionally, research has concentrated on recognizing why patients are noncompliant and the strategies to increase compliance. ${ }^{9}$

The pattern of treatment has been changed drastically after the emergence of programmable chips for chronic ailments patients like cancer, multiple sclerosis and osteoporosis. In conditions where frequent daily injections are needed mostly in case of chronic illnesses where regular pain management is required, can have benefits from this technology, ${ }^{9}$

Therefore, if a drug delivery device is capable of being controlled from outside the body and can release many types of drugs continuously and also implantable safely in human body, will be greatly advantageous. Many factors that must be come into account for manufacturing of effective and successful drug delivery system few includes how it is being processed, reliability of material, biocompatibility and drug release pattern. ${ }^{10}$ 


\section{Microchips}

Microchips are smart medical implants that can dispense drugs into the bloodstream by getting wireless signals sent to them from the medical implant communication service (MICS). ${ }^{11}$ Localized delivery, delivery on demand, controlled drug release, dose checking and physician option to remotely adjust treatment schedule are advantages of these chips. ${ }^{12}$ Implantable medical device is not a new term; such devices are in use such as pace-maker and pain pumps. ${ }^{\mathbf{1 3}}$ This smart implant can be injected under the skin in the doctor's office in about 30 minutes using a local anesthetic and lasts about four months before needing to be replaced. ${ }^{14}$

\section{How it works}

Microchip based implants are programmed to release drugs inside the body through wireless system. This contains micro reservoir where drug is stored and it is sealed with platinum and titanium membrane. This is planted in human body under the skin and when the drug release is needed, the device is activated through wireless signal and an electrical current is applied which melt the membrane and release the drug inside the body. When drug reservoir is empty, the next dose can be delivered through another reservoir.
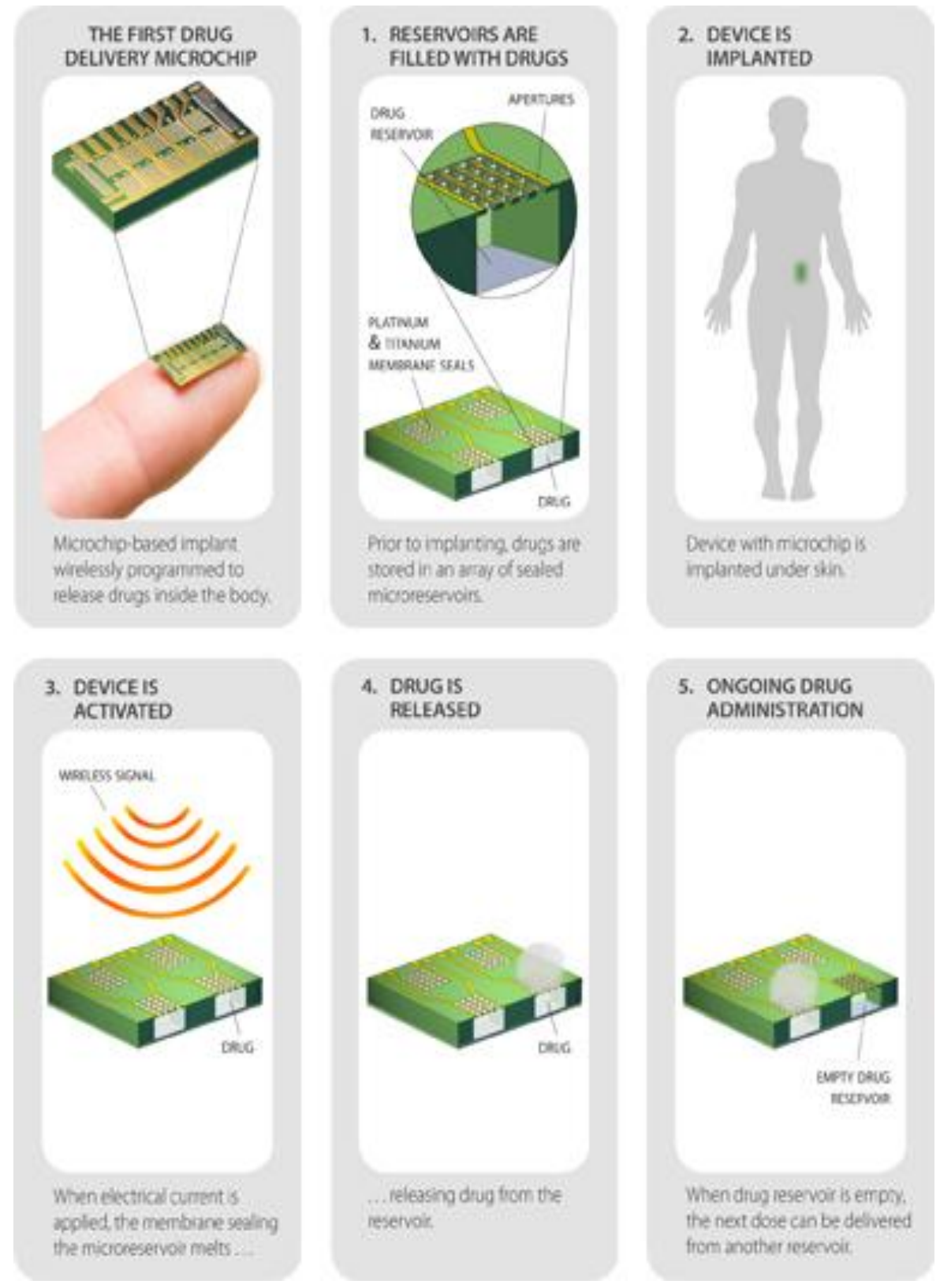

Figure 1: Working of Microchip for wireless drug delivery system (source:www.mchips.com)

\section{CLINICAL TRIALS}

Microchip based drug delivery device trial was first performed clinically in eight osteoporotic postmenopausal women where the discrete doses of lyophilized hPTH(1-
34) containing devices were implanted. The dose has been released once daily through wireless controlled drug delivery system for 20 days. The hPTH(1-34) was analyzed for bioequivalence, safety, tolerability and pharmacokinetics. It is revealed that release of drug from 
device on daily basis increased bone formation. No adverse effect or toxicity seen and device did not affect quality of life. $^{16}$

\section{Application of WDDS in Osteoporosis:}

Osteoporosis is treated by Human parathyroid hormone fragment (1-34) [hPTH(1-34)]. It occurs if the balance of bone resorption and formation process disturbed. In osteoporosis bone mineral density is lost which causes bone fractures. According to World Health Organization about 9 million fractures per year in the world are due to osteoporosis, and contribute significantly to disability rates. ${ }^{17}$ The projected cost of these fractures in US is estimated as more than $\$ 20$ billion ${ }^{18}$ The drugs used to treat osteoporosis are classified in two classes, one type is bone resorption inhibitors that include calcitonin, bisphosphonates, and estrogens, , and the second type are anabolic agents, such as human parathyroid hormone [hPTH(1-84)] and teriparatide [hPTH(1-34)]. FDA given approval for Eli Lilly and Company's teriparatide (U.S. and European Union trade names FORTEO and FORSTEO, respectively) in 2002. The Teripartide contains hPTH(1-34) as the active agent. It is indicated for osteoporosis treatment in both who are at fracture risk. The estimated number of teriparatide users in the United States in 2010 were 50, 000. ${ }^{\mathbf{1 9}}$ Regular hPTH(1-34) administration encourage osteoclast activity, which casue bone loss. $^{20,21}$ On the other hand, intermittent or pulsatile delivery of hPTH(1-34) is used as anabolic therapy and incite osteoblast activity (bone formation) greater than osteoclast activity, and so the bone mineral density and mass increased. ${ }^{22}$ Daily administration of 20 - to $40-\mathrm{mg}$ doses of hPTH (1-34) through subcutaneous route for around 2 years cause a decrease in fracture incidence and it is with acceptable profile of safety. ${ }^{\mathbf{2 3}, 24}$ But the patient compliance for daily subcutaneous injections is poor. ${ }^{25}$ The first candidate which was selected for human trial was hPTH(1-34). The programmable implant was used in clinical trials that deliver hPTH(1-34) at scheduled intervals, with a similar PK value as in case of daily subcutaneous injections. ${ }^{16}$

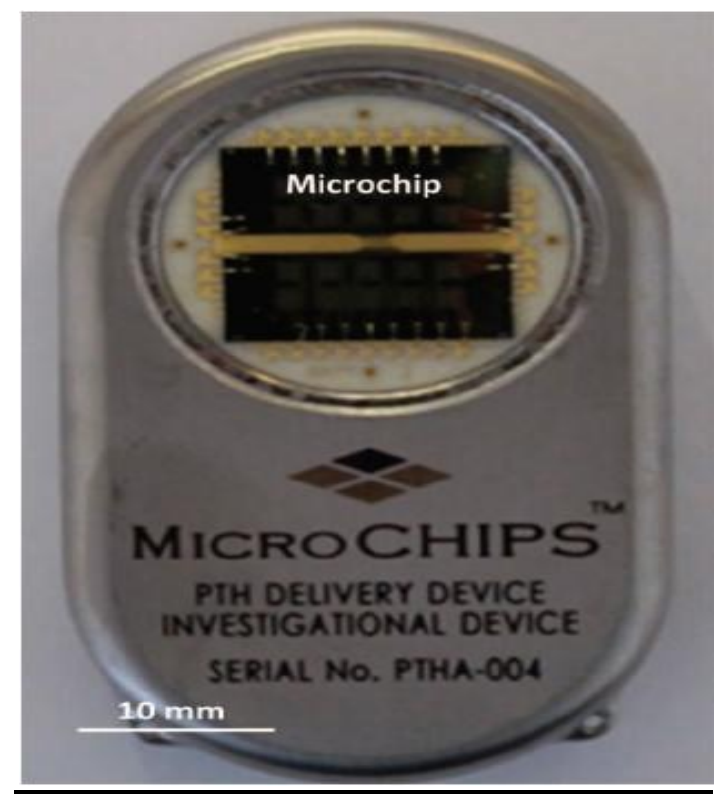

Figure 2: Microchip used in human trial (source:www.mchips.com \& R.Farra et al., 2012)

\section{CHALLENGES AND OPPORTUNITIES}

Although the microchips based wireless drug delivery system seems to be perfect for patients with chronic ailments but there are some problems in the commercial development of these devices that includes:

$>$ complexity (as multiple system interaction is required, and failure risk is higher),

$>$ cost is high

$>$ potentially harmful (a minor surgery is needed)

$>$ obtrusive (existing device has a large size) and

$>$ Limitation in drug loading (only few drugs are feasible to be loaded for a long therapy). Like every other technology, these factors will have to be eliminated and the factors for success of this technology will be:

$>$ validated proof that technology is feasible,

$>$ an approval from regulatory body

$>$ more stress advanced new delivery systems

$>$ capability to meet important medical requirement

\section{SUBJECTS AND METHOD:}

A brief awareness to the WDDS has been given to the patients and then the study was performed. A questionnaire has been prepared after reviewing literature in view of objective of study based quantitative approach. The data has been collected from patients at random who are under treatment at primary, secondary and tertiary health care units by a cross sectional study among three different categories of participants those might be the main stakeholder for future use of WDDS. Study design of data collection is shown in Figure 3.

A total of 267 patients were approached out of which 203 were agreed participated in the survey. For each category of participants 50 were randomly selected to fill questionnaire forms for data collection and compilation.

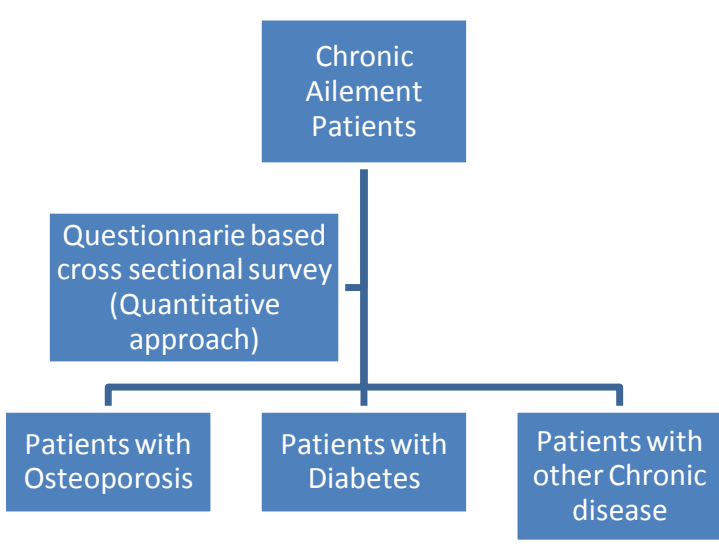

Figure 3: Study Design for data collection QUESTIONNAIRE LAYOUT:

The participants were required to fill a structured questionnaire comprising of 20 questions. It covered all aspects of Wireless Drug delivery system (WDDS) and its future use in the patients with chronic illnesses In addition to these questions, personal profile of patients such as name, age group, occupation was asked. Name and occupation declaration was optional because it may cause 
Tariq Ali et al

Journal of Drug Delivery \& Therapeutics; 2013, 3(1), 14-19

reluctance to give actual information. An additional space was provided for comment and feedback.

\section{INFORMED CONSENT:}

The objective of this survey was explained after giving a brief introduction to WDDS and verbal consent was obtained from the patients. It was also informed that the data will be used for survey purpose only. Most of the participant filled the questionnaire on their own and few were interviewed as well to assist them in filling the questionnaire.

Table 1: Patient Response after brief awareness on WDDS

\begin{tabular}{|c|l|c|c|c|}
\hline S.NO & \multicolumn{1}{|c|}{ STATEMENT } & $\begin{array}{l}\text { Osteoporosis } \\
\text { patients }\end{array}$ & $\begin{array}{l}\text { Diabetic } \\
\text { Patients }\end{array}$ & $\begin{array}{l}\text { Other } \\
\text { Chronic } \\
\text { Patients }\end{array}$ \\
\hline $\mathbf{1}$ & $\begin{array}{l}\text { Patients agreeing that new technology development can make their lives } \\
\text { comfortable. }\end{array}$ & $87 \%$ & $92 \%$ & $81 \%$ \\
\hline $\mathbf{2}$ & $\begin{array}{l}\text { Patients who can rely on new development in the field of drug delivery } \\
\text { after trials in the western world. }\end{array}$ & $62 \%$ & $79.00 \%$ & $56.00 \%$ \\
\hline $\mathbf{3}$ & $\begin{array}{l}\text { Patients who think that the surgical procedure will be better option for } \\
\text { medication intake. }\end{array}$ & $45 \%$ & $56.00 \%$ & $63.00 \%$ \\
\hline $\mathbf{4}$ & $\begin{array}{l}\text { Patients have consent if a minor surgery can make it avoidable for a } \\
\text { year of medication intake through injections. }\end{array}$ & $78 \%$ & $86 \%$ & $81.00 \%$ \\
\hline $\mathbf{5}$ & $\begin{array}{l}\text { Patients who think that wireless system will work properly and it will } \\
\text { not be with any technical problem such as battery, weak signals etc. }\end{array}$ & $35 \%$ & $47.00 \%$ & $50 \%$ \\
\hline $\mathbf{6}$ & Patients have a blind-faith on physician advice for new WDDS. & $55.00 \%$ & $54.00 \%$ & $51.00 \%$ \\
\hline
\end{tabular}

\section{RESULTS:}

A total of 203 patients were responded to participate in the survey out of 267 approached patients (response factor was $76 \%$ ). The samples were selected in such a way that from each category 50 participants filled the questionnaire and responses were recorded. The results showed that greater percentage of participants agreed that new technological advancement is making their life easier and comfortable. About $87 \%$ of the patients think that this statement is right. $65 \%$ of participant think that new advancement in the field of drug development will be beneficial for them among those highest positive thinkers were diabetic patients.

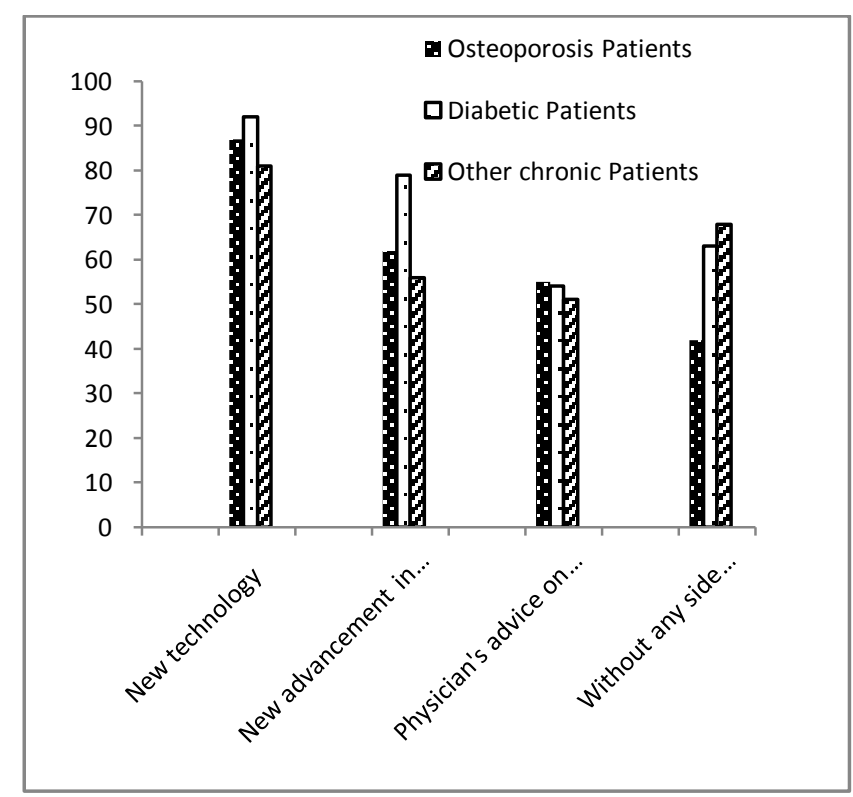

Figure 4: Confidence level of chronic ailment patients on technological advancement in Karachi, Pakistan
A half of the participants believe that surgical procedure can be a better option for medication intake. Patients who think that minor surgery is a better option to take a medicine instead of taking medication for years through injection was about $82 \%$. More than $50 \%$ patients have the idea that this system will be with technical problems.

\section{DISCUSSION:}

The survey revealed that most of the chronic ailment patients in Karachi, Pakistan will response in affirmative for the adaptability of new technology. But the $\%$ of adaptability may be lesser for WDDS as compare to new technology like cell phone or any other new technology. This may be because of the fact the people are reluctant to take risk for health management except where they have solid data or if they say someone by themselves who have benefited with the technology. There might be the reason involve that the new technology may be with some side effects or with some other technical issue to use them. The technical issue may be battery, or weaker signals of device that may cause hindrance in the use of WDDS.

For the purpose of ease in taking medication, overall they prefer to go through a minor surgery instead of taking daily injections. A surprising but good thing which has been revealed that for the matter of adapting this new technology they will not blindly trust on their physician but it will the case of acceptability only if they have strong data and/or observed someone used it personally. It has two possible options either they are not eager to take risk or they want to have knowledge by themselves. 


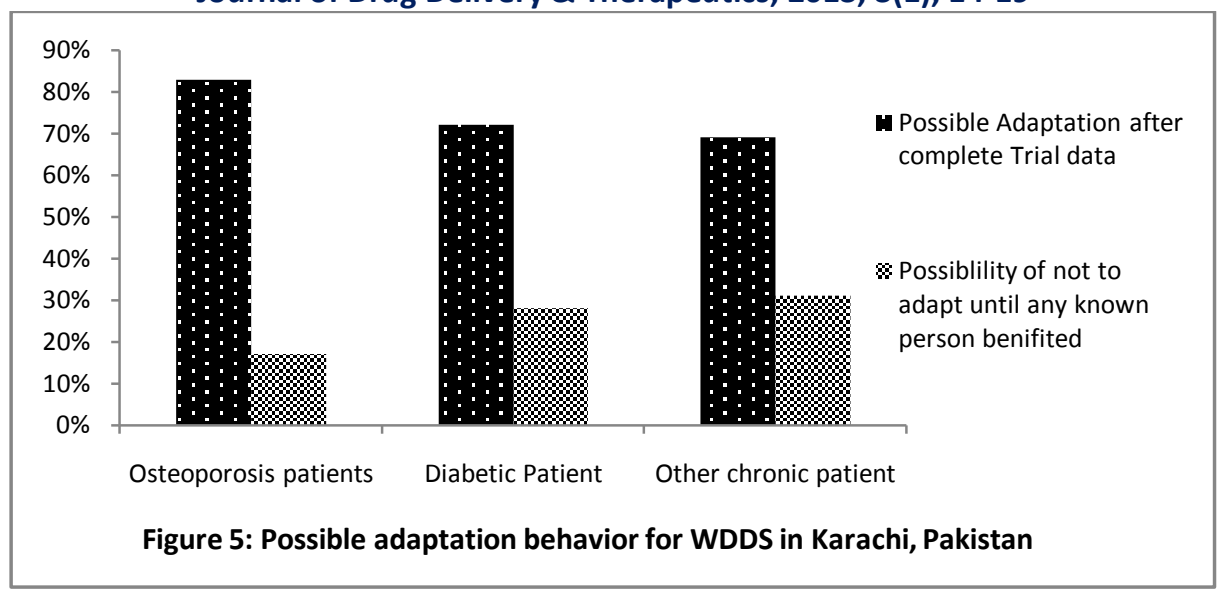

\section{CONCLUSION:}

The union of drug delivery and electronic technologies provides physicians a better link with the health of patient. ${ }^{7}$ Technical success is a precondition but does not guarantee commercial success. New drug delivery system development are always with successes and failures so it is unrealistic to predict about the innovative product future.

Chronic Patient in Karachi, Pakistan may adopt the technology and over all a positive response will be there if the technology will come to them with strong data, lesser side effect and easy use.

It seems to have an innovative discovery for mankind which has pharmacy on a chip, enhancing patient compliance. In the end, WDDS provides a new treatment option for physician where effectiveness of conventional dosing methods is inconvenient when estimated on the parameter of pain, efficacy and safety. WDDS minimize the compliance problem and leads to a future where you have fully automated drug regimens.

\section{REFERENCE:}

1. Stone G.W, Ellis S. G, Cox D.A, Hermiller J, O'Shaughnessy C, Mann J. T, Turco M, Caputo R, Bergin P, Greenberg J,Popma J. J, Russell M. E; TAXUS-IV Investigators, A polymerbased, paclitaxel-eluting stent in patients with coronary artery disease. N. Engl. J. Med. 2004, 350, 221-231

2. Prescott J. H, Lipka S, Baldwin S, Sheppard Jr. N. F, Maloney J. M, Coppeta J, Yomtov B, Staples M. A, Santini Jr. J. T, Chronic, programmed polypeptide delivery from an implanted, multireservoir microchip device. Nat. Biotechnol. 2006, 24, 437438 .

3. Santini Jr. J. T, Cima M. J, Langer R, A controlled-release microchip. Nature; 1999, 397, 335-338.

4. Richards Grayson A. C, Choi I. S, Tyler B. M, Wang P. P, Brem H, M. Cima M. J, Langer R, Multi-pulse drug delivery from a resorbable polymeric microchip device. Nat. Mater.; 2003, 2, 767-772 (2003)

5. Lanvan D. A, McGuire T. Langer R., "Small-scale systems for in-vivo drug delivery." Nature Biotechnology; 2003, 21, 1184 1191

6. Santini J, Richards A. C, Scheidt R, Cima M. J \& Langer R., "Microchips as controlled drug delivery devices." Angew Chem.Int.Ed; 2000,39,2396-2407

7. Dolan B. "Results from wireless, implantable drug delivery device study". Science Transitional Medicine, 2012

8. Wertheimer A. "Medication Compliance Research: Still So Far to Go".the Journal of Applied Research; 2003, 3, 3.

9. Maloney J.M, Uhland S, Polito b, Sheppard N, Pelta C, Santin J.T. "electro thermally activated microchip for implantable drug
FUTURE PROSPECTS: According to the Robert Ferra, the data obtained through studies validate the microchip approach to multi-year drug delivery without the need for daily injections, can improve can improve many chronic diseases like osteoporosis management. They are also planning to develop products for use in important disease, multiple sclerosis, cancer and chronic pain

MicroCHIPS is working on microchip-based implant that may include as many as 400 doses in a device for less frequent dosing regimens. It is expected that MicroCHIPS will file an application regulatory approval of first microchip device in $2014 .^{26}$

ACKNOWLEDGEMENT: Authors wish to acknowledge Dr. Muhammad Harris Shoaib who is a role model in pharmaceutical research field that kindle to move forward. Authors are very much thankful to administration of primary, secondary and tertiary patient care units for providing the opportunity to complete the survey.

CONFLICT OF INTEREST: Authors declare that there is no conflict of interest.

delivery \& biosensing, journal of controlled release; 2012, 109 244-255

10. Viral S, Patel K, Upadhyay U. M "Injecting New Ideas Into Drug-Delivery Systems-A Brief Review on Microchips as Controlled Drug-Delivery System". The Pharma Review; Jan 2010

11. Johnson R.C. "Wireless Implant Meters Drug Doses".2012

12. Staples M. "Microchips and controlled-release drug reservoirs". Wiley online library . 2010

13. Maloney J. M. "AN IMPLANTABLE MICROFABRICATED DRUG DELIVERY SYSTEM". International Mechanical Engineering Congress. 2003.

14. Pandolfino J.E, Richter J.E, Ours T, Guardino J.M , Chapman J, Kahrilas P T. "Ambulatory Esophageal pH Monitoring Using a Wireless System". The American Journal of Gastroenterology; 2003, 98, 740-749;

15. MicroCHIPS, Inc., Waltham, MA 02451,USA(http://www.mchips.com/technology/technology.html )

16. Farra R, Sheppard Jr. N. F, McCabe L, Neer R. M., Anderson J. M., Santini Jr. , J. T. Cima M. J., Langer R., First-in-human testing of a wirelessly controlled drug delivery microchip. Sci. Transl. Med; 2012, 4, 122ra21

17. WHO Scientific Group on the Assessment of Osteoporosis at Primary Health Care Level, Summary Meeting Report, Brussels, Belgium, 5-7 May 2004 (WHO Press, Geneva, Switzerland, 2007) 
18. Burge R, Dawson-Hughes B, Solomon D. H, J. Wong J. B, King A, Tosteson A, Incidence and economic burden of osteoporosisrelated fractures in the United States, 2005-2025. J. Bone Miner. Res; 2007, 22, 465-475

19. Eli Lilly and Co., Annual Report and Proxy Statement; http://investor.lilly.com/annuals.cfm

20. Hock J. M, Gera I, Effects of continuous and intermittent administration and inhibition of resorption on the anabolic response of bone to parathyroid hormone. J. Bone Miner. Res.; 1992, 7, 65-72.

21. Dobnig H, Turner R. T, The effects of programmed administration of human parathyroid hormone fragment (1-34) on bone histomorphometry and serum chemistry in rats. Endocrinology; 1997, 138, 4607-4612

22. Frolik C. A, Black E.C, Cain R. L, Satterwhite J. H, BrownAugsburger P. L, Sato M, Hock J. M., Anabolic and catabolic bone effects of human parathyroid hormone (1-34) are predicted by duration of hormone exposure. Bone; 2003, 33, 372-379
23. Neer R. M, Arnaud C. D, Zanchetta J. R, Prince R, Gaich G. A., Reginster J. Y., Hodsman A. B., Eriksen E. F. , Ish-Shalom S., Genant H. K., Wang O., Mitlak B. H. , Effect of parathyroid hormone (1-34) on fractures and bone mineral density in postmenopausal women with osteoporosis. N. Engl. J. Med.; 2001, 344, 1434-1441

24. Jerome C. P., Burr D. B. , Van Bibber, T., Hock J. M. , Brommage R. , Treatment with human parathyroid hormone (134) for 18 months increases cancellous bone volume and improvestrabecular architecture in ovariectomized cynomolgus monkeys (Macaca fascicularis). Bone; 2001, 28, 150-159

25. Taylor K, Gold D.T , Miller P, Chen P, Wong M, Krohn K, Teriparatide therapy in a community setting: Persistence and use of other osteoporosis medications in DANCE, paper presented at the 30th Annual Meeting of the American Society for Bone and Mineral Research, 2008.

26. http://www.mchips.com/news/releases/12_Feb_16_pr.html 